Résumés des conférences et travaux

\title{
Liste des doctorats soutenus à la section pendant l'année 2008-2009
}

par ordre alphabétique des noms d'auteur

\section{OpenEdition}

\section{Journals}

Édition électronique

URL : https://journals.openedition.org/ashp/950

DOI : 10.4000/ashp.950

ISSN : 1969-6310

Éditeur

Publications de l'École Pratique des Hautes Études

Édition imprimée

Date de publication : 2 février 2011

Pagination : xii-xiv

ISSN : 0766-0677

Référence électronique

"Liste des doctorats soutenus à la section pendant l'année 2008-2009 », Annuaire de l'École pratique des hautes études (EPHE), Section des sciences historiques et philologiques [En ligne], 141 | 2011, mis en ligne le 22 février 2011, consulté le 06 juillet 2021. URL : http://journals.openedition.org/ashp/950 ; DOI : https://doi.org/10.4000/ashp.950

Ce document a été généré automatiquement le 6 juillet 2021.

Tous droits réservés : EPHE 


\section{Liste des doctorats soutenus à la section pendant l'année 2008-2009}

par ordre alphabétique des noms d'auteur

1 Lectiones Sententiarum. Étude de manuscrits de la bibliothèque du collège de Sorbonne: la formation des étudiants en théologie à l'université de Paris à partir des annotations et des commentaires sur le Livre des Sentences de Pierre Lombard (XIII et XV $\mathrm{XV}^{e}$ siècles), par Claire ANGOTTI, sous la direction de M. Jacques VERGER, le 5 décembre 2008.

2 Louis Charles Auguste Steinheil (1814-1885) : vie et ceuvre, par Stanislas ANTHONIOZ, co-tutelle sous la direction de M. Jean-Michel LeNIAUd (EPHE) et de M. Yves CHRISTE (université de Genève), le 10 octobre 2008.

3 Jean-Louis Pascal (1837-1920) architecte. La tradition de l'École des beaux-arts à l'épreuve du romantisme, par Anne BAZIRE, sous la direction de M. Jean-Michel LENIAUD, le 16 mars 2009.

4 La communication scientifique et la révolution numérique (1969-2009): analyse d'une période de mutation dans une perspective historique, par Guylaine BEAUDRY, sous la direction de M. Frédéric BARBIER, le 27 juin 2009.

5 Histoire, religion et science dans les derniers écrits d'Ernest Renan, par Domenico PAONE, sous la direction de M. Jacques Le RIDER (EPHE) et de M. Giuliano CAMPIONI (Universita del Salento, Lecce), le 30 mars 2009.

6 Madagascar et la Carreira da India, 1500-1609, par Manuel CARVAlHo VicENTE, sous la direction de $\mathrm{M}^{\mathrm{me}}$ Dejanirah SILVA-Couto, le 18 décembre 2008.

7 Autour d'Étienne Colaud. Recherches sur les enlumineurs parisiens sous le règne de François I ${ }^{e r}$, par Marie-Blanche Cousseau, sous la direction de M. Guy-Michel Leproux, le 21 mars 2009.

8 L'Alhambra, le rêve de l'Europe. Étude comparée de l'Orientalisme en France et en Allemagne au $X I X^{e}$ siècle, par Lorraine DECLETY, co-tutelle sous la direction de M. Jean-Michel LENIAUD (EPHE) et de M. Bruno KLEIN (université de Dresde), le 11 décembre 2008.

9 Le château de Saint-Cloud des Gondi aux Orléans: architecture et décors (1577-1785), par Michael DeCRossas, sous la direction de M. Guy-Michel LeProux, le 3 décembre 2008. 

par Julie DuMONTEIL, co-tutelle sous la direction de M. Jacques LE RIDER (EPHE) et de M. Gerd SCHWERHOFF (Technische Universität Dresden), le 28 novembre 2008.

Electre et Oreste dans le théâtre du XX $X^{e}$ siècle, par Silvia GIULIANI, co-tutelle sous la direction de M. Jacques Le RIDER (EPHE) et de M. Guido PADUAno (université de Pise), le 12 mars 2009.

12 Les armoiries de femmes en France, des origines au XVI e siècle. Sources, usage et fonction, par Marie GrÉGOIRE, sous la direction de M. Michel PASTOUREAU, le 21 mars 2009.

INS et INSAN : racines ou dérivations?, par Ali-Rabah IMEKHLEF, sous la direction de M. Henri HugONNARD-ROCHE, le 9 décembre 2008.

Préservation et présentation du patrimoine archéologique dans les musées syriens au $\mathrm{XX}^{e}$ siècle, par Randa ISMAIL, sous la direction de M. Michel TERRASSE, le 8 novembre 2008.

Essai d'histoire politique du monothélisme à partir de la correspondance entre les empereurs byzantins, les patriarches de Constantinople et les papes de Rome, par Marek JANKOWIAK, cotutelle sous la direction de M. Denis FeISSEL (EPHE) et de M. Adam ZıoLKowsKI (université de Varsovie), le 30 mai 2009.

Une famille de libraires spécialisés à Paris : la dynastie Jombert et le commerce culturel dans l'Europe des Lumières (1686-1824), par Greta KAUCHER, sous la direction de M. Frédéric BARBIER, le 12 juin 2009.

17 Les papyrus «d'El-Hibeh» à la $21^{e}$ dynastie. Étude philologique et prosopographique, par Dominique LEFÈVRE, sous la direction de M. Pascal VeRnUs, le 13 septembre 2008.

18 Recherches sur les communautés festives dans la « vieille Grèce » (IIe siècle a. C.-IIIe siècle p. C.). Contribution à l'étude du contexte historique et sociologique des cultes dans la Grèce romaine, par Paraskevi MARTZAVOU, sous la direction de M. Jean-Louis FERRARY, le 15 décembre 2008.

$19 L a$ «reglirung dero [...] estampen-cabinets». La formation et le développement de la collection des estampes et dessins à Dresde depuis la fondation de la Kunstkammer (1560) jusqu'au premier inventaire du Kupferstich-Kabinett (1738), par Christien MELzER, co-tutelle sous la direction de M. Michel Hochmann (EPHE) et de M. Bruno KLEIN (université de Dresde), le 18 juin 2009.

20 Vies des pénitentes et des femmes ermites dans l'hagiographie géorgienne (selon les manuscrits des $\mathrm{X}^{e}$-XI ${ }^{e}$ siècles), par Nana MiRAchVILI-SpRINGER, sous la direction de M. Jean-Pierre MAHÉ, le 6 décembre 2008.

21 AB ZOHR: analyse générale du texte avestique et moyen perse (Yasna 63-69). Traduction et commentaires des paragraphes spécifiques du texte (Yasna 65. 6-14; 68. 1-15), par Bahman MORADIAN, sous la direction de M. Philip HUYSE, le 4 décembre 2008. Les adjectifs primaires en *-NO- du grec ancien signifiant "dense, compact ", "agréable, charmant" et "vénérable, sacré». Étude sémantique, étymologique et suffixale, par Pierre RAGOT, sous la direction de M. Charles DE LAMBERTERIE, le 29 novembre 2008. La participation des femmes au journalisme politique et littéraire. Italie et France entre XIX ${ }^{e}$ et $X^{e}$ siècle, par Maria Cecilia VIGNUZZI, co-tutelle sous la direction de M. Gilles PÉcout (EPHE) et de $\mathrm{M}^{\mathrm{me}}$ Ilaria PoRCIANI (université de Bologne), le 23 juin 2008. 
INDEX

Thèmes : Doctorats soutenus à la Section 